\title{
Using Blended Learning To Facilitate The Mathematical Thought Processes Of Primary School Learners In A Computer Laboratory: A Case Study In Calculating Simple Areas
}

N. Naidoo, (E-mail: nirenn@telkomsa.net), Durban University of Technology, South Africa R. Naidoo, (E-mail: naidoor@dut.ac.za), Durban University of Technology, South Africa

\begin{abstract}
Primary school learners' first encounters with mathematics in a traditional learning environment often create lifelong 'math phobia.'(Papert 1980) The situation in a country emerging from an oppressive education system designed to educationally disempower the majority of the population is much worse. The typical scenario in a previously disadvantaged South African primary school is a classroom filled beyond capacity with the educator struggling to establish an effective learning environment. Thus the educator resorts to rote learning, drill and practice and 'chalk and talk' methods of teaching. The individual needs and levels of learners are disregarded and blanket assessment methods are employed (Naidoo and Naidoo 2006b). Collaborative learning is minimal or non-existent. These traditional teaching strategies often disregard cultural and social factors, and pre-knowledge frames of learners. Furthermore there is a dire shortage of qualified mathematics educators in the South African schooling system. Therefore there is an urgent need for alternative teaching and learning strategies to address the teaching of mathematics in primary schools. The introduction of networked computer laboratories to previously disadvantaged South African primary schools enables the use of computers as powerful tools to analyze the thought processes of learners during their early encounters with mathematics. A blended learning approach using a networked computing environment and LOGO mathematics to facilitate the teaching and learning of area in a Grade 5 class produced significantly higher grades and an enhanced learning experience, both for learners and the educator, as compared to a second Grade 5 class utilizing traditional teaching and learning methods only. This study entailed the use of software to promote collaborative learning encompassing both learner-learner and learner-educator interaction. Apart from the educator using the computer as a medium of instruction via the software, learners were allowed to actively provide input. Furthermore the software allowed the educator to view learners' progress during activities and provide real-time input via the computer.
\end{abstract}

\section{INTRODUCTION}

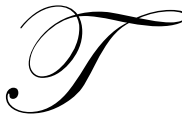

he research was motivated by a study performed at the Durban University of Technology on first year university students understanding of elementary calculus (Naidoo 1998). One of the results of the research is that students do not have a basic understanding of area, volume and perimeter. They remembered basic formulae. It is clear that these concepts were not understood at the primary school level. At primary school traditional learning is performed (Naidoo and Naidoo 2006a). With the introduction of information technology in South African primary schools, it has become necessary to explore avenues to maximize 
the use of computer assisted learning. There exists an abundance of research into the effectiveness of this learning medium and the manner that it can be implemented (Karuppan 2001).

Dovetailing with the above is the fact that primary school learners' first encounters with mathematics in a traditional learning environment often create lifelong 'math phobia' (Papert 1980). This is most evident at tertiary level where students experience difficulty due to a poor grasp of basic mathematical concepts. The typical scenario in a previously disadvantaged South African primary school is a classroom filled beyond capacity with the educator struggling to establish an effective learning environment. Thus the educator resorts to rote learning, drill and practice and 'chalk and talk' methods of teaching. The individual needs and levels of learners are disregarded and blanket assessment methods are employed (Naidoo and Naidoo 2006b). Collaborative learning is minimal or non-existent. These traditional teaching strategies often disregard cultural and social factors, and pre-knowledge frames of learners. Therefore there is an urgent need for alternative teaching and learning strategies to address the teaching of mathematics in primary schools. The introduction of networked computer laboratories to previously disadvantaged South African primary schools enables the use of computers as powerful tools to analyze the thought processes of learners during their early encounters with mathematics. Such a learning environment lends itself to the teacher being a facilitator thus addressing the problem of the dearth of qualified mathematics educators in South Africa.

The researcher sought to maximize the opportunities provided by a networked computing environment to enhance the learners' experiences and interaction through discovery learning in a mathematics classroom, the latter being a computer laboratory. To achieve the aforementioned objectives 2 groups comprising 20 Grade 5 learners each were exposed to the teaching and learning of area with 1 group using Logo mathematics in the computer laboratory and the other group using traditional classroom based teaching and learning. The reason for area being chosen is that educators often find learners having difficulty with the concept area. This may be due to misconceptions, confusing area with perimeter or a total lack of knowledge of the concept (Leung 2001). In addition, the researcher used a blended learning approach due to the fact that computers, and especially a networked computing environment, were relatively new phenomena to South African primary school learners Thus a combination of face-to-face interaction encompassing conventional learning strategies, and the use of computers as teaching/learning media would be most suitable (Naidoo and Naidoo 2006a).

\section{THEORETICAL FRAMEWORK}

Integral to this study are the constructivist approach and collaborative learning. Furthermore the learner is perceived as an epistemologist and culture is viewed as having an indelible impact on the manner in which the learner interacts with the learning experience. Theories concerning the developmental stages of the learner as well as preknowledge frames and deep and surface structures are central to this study.

\subsection{The Constructivist Approach And Collaborative Learning}

This study is set within a constructivist framework with collaborative learning playing an integral role. According to the constructivist approach a key aim in any learning situation is that the learner should actively seek to make sense of the world (Jolliffe 2001). Furthermore learning is seen as a constructive process with the learner building an internal representation of knowledge. The learner would have to engage both social and cultural elements to complete activities and tasks. Collaborative learning is a method of learning in which learners are placed in small groups or pairs in order to achieve a common academic goal (Gokhale 1995). This implies that learners are responsible for the learning of other group members as well as their own. The proponents of collaborative learning claim that shared learning enables learners to be responsible for their own learning, become critical thinkers and engage in discussion, which would invariably lead to an improvement in social skills (Totten, Sills, Digby and Russ 1991 as cited by Gokhale 1995). 


\subsection{The Learner As An Epistemologist}

As recently as the past century it was generally accepted that children's thoughts were less sophisticated, less complex but qualitatively similar to adults. However this idea has gradually evolved into one that espouses that children think in a different way from adults and reach distinct conclusions from the same data. One of the most influential theorists in this regard was Jean Piaget.

The cognitive-developmental theory developed by Piaget states that children and adolescents continuously construct intelligence as they operate and discover their world. The theory further proposes that hereditary and environmental factors determine the underlying causes of child development (Berk 2000). However, the environment affects how and what the child learns while the process of development is determined from within the child depending on the stage of the cognitive structure. Thus the underlying belief is that biological development drives the movement from one cognitive stage to the next (Huitt and Hummel 2003). Piaget identified four distinct stages of cognitive development (Figure1).

Piaget's theory is open to criticism in that his research methods were primarily based on case studies. Data from cross-sectional studies of adolescents are not supportive of his view that individuals will automatically progress to the next stage of cognitive development as they mature biologically. A body of research (Kuhn et al 1977) indicates that only 30 to $35 \%$ of high school seniors attain the cognitive development stage of formal operations (Figure 2). Furthermore the converse may be true in that learners may attain the formal operational stage of cognitive development before they reach adolescence.

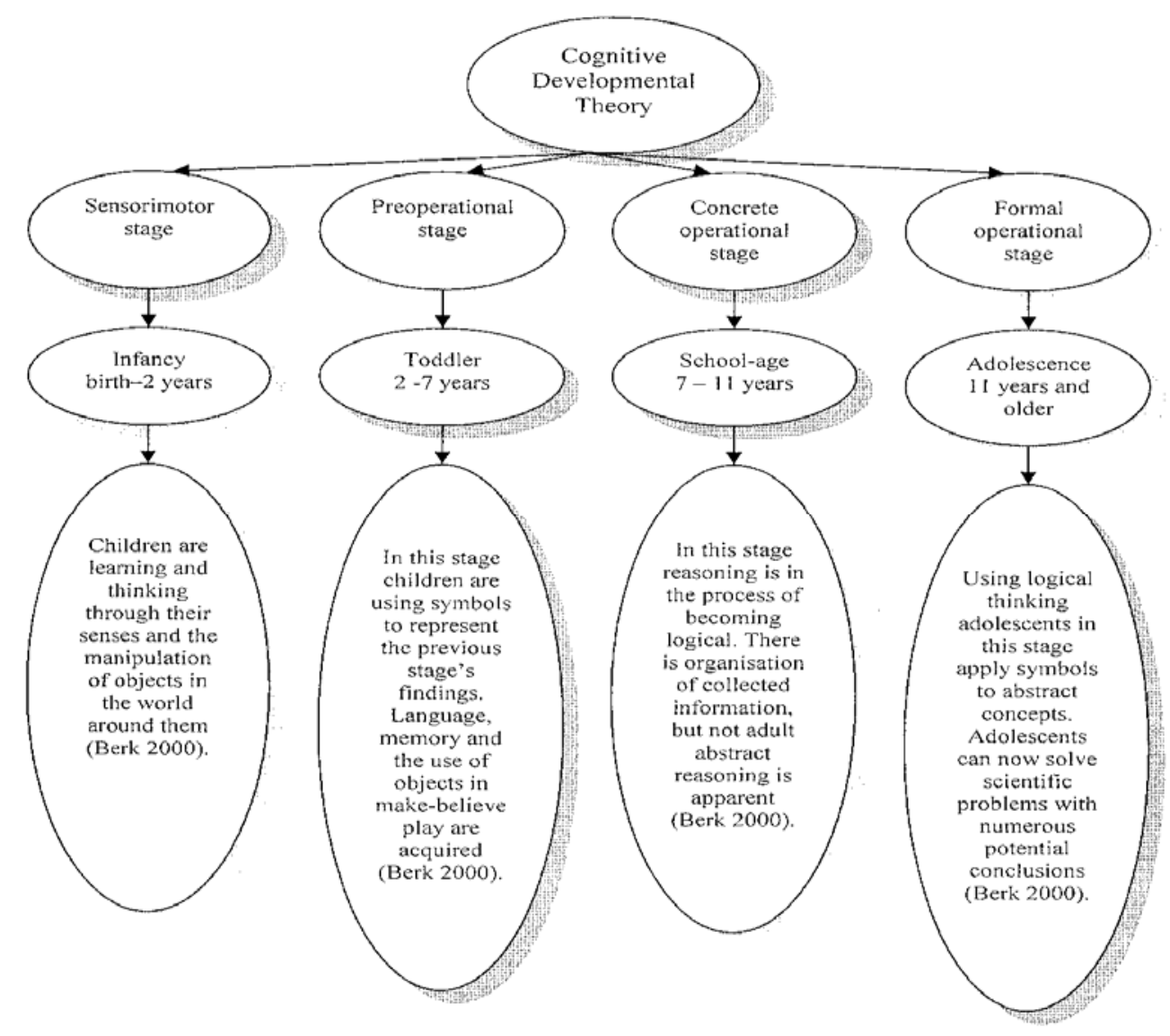

Figure 1: Piaget's stages of cognitive development (Berk, 2000) 


\section{Attainment of Formal Operational Thinking by High School Students}

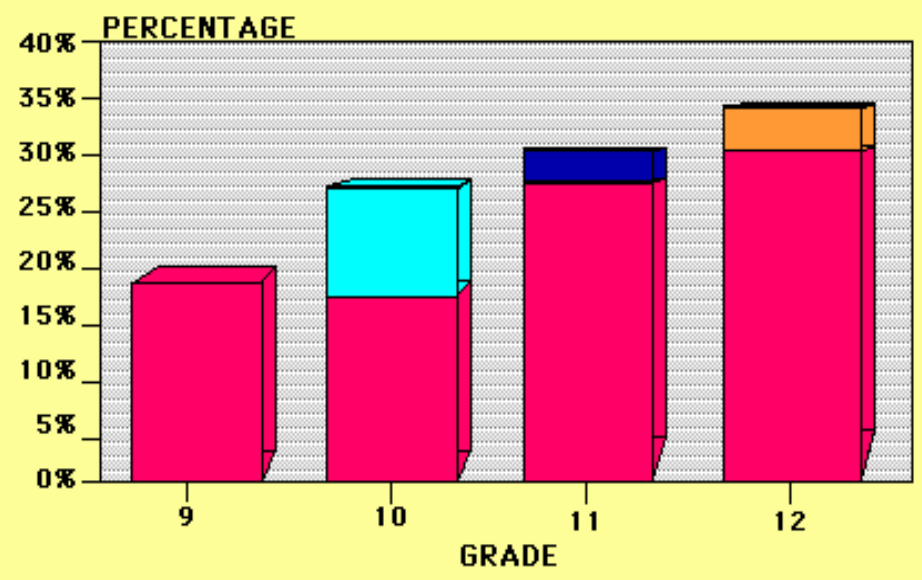

Figure 2: Attainment of formal operational thinking by adolescents (Renner et al 1976)

Papert (1980), like Piaget, views children as builders constructing their own intellectual structures. Children acquire a vast quantity of knowledge well before going to school and without being taught. However Papert differs with Piaget in the area of why some learning occurs so early while others have to be deliberately imposed as formal instruction later on (Papert 1980). He postulates that the surrounding culture of the learners as a source of materials for the construction of their intellects is the critical factor in the development of children as epistemologists. Often the culture that the learner is in displays a lack of formal materials and a cultural block, as in the case of formal mathematics.

We shall see again and again that the consequences of mathophobia go far beyond obstructing the learning of mathematics and science. They interact with other endemic "cultural toxins," for example, with popular theories of aptitudes, to contaminate peoples' images of themselves as learners. Difficulty with school math is often the first step of an invasive intellectual process that leads us all to define ourselves as bundles of aptitudes and ineptitudes, as being "mathematical" or "not mathematical," "artistic" or "not artistic," "musical" or "not musical," "profound" or "superficial," "intelligent" or "dumb." Thus deficiency becomes identity and learning is transformed from the early child's free exploration of the world to a chore beset by insecurities and self-imposed restrictions (Papert 1980: 8).

Papert proposes the use of computers in mathematics education as a means of overcoming these cultural barriers. He postulates that children can learn to use computers in a masterful way and that learning to use computers can change the way they learn everything else (Papert 1980: 8). To this end the use of LOGO mathematics is central. As opposed to the traditional learning environment where the educator instructs and the learner follows, in this learning environment the learner assumes the role of instructor and programmer. Furthermore the learners' interaction with LOGO via the computer is not a one-way process. The program provides feedback in such a manner as to provide learners with a choice as to how they want to react to it. LOGO is a computer programming language designed for learning. It allows the learner access to creating screen effects and to the mathematical concepts which underlie them (Noss 1998). There have been a number of longitudinal studies which have sought to analyse the power of this environment from a mathematical perspective, and which have illustrated that children are able to explore and use a variety of mathematical ideas in a wide range of contexts (Papert 1979; Hoyles 1985). The body of research suggests that learners working with LOGO, by creating and interacting with objects that are visible, quantifiable, and adhere to conventional mathematics, build connections between spatial and algebraic thinking. Mathematics becomes more concrete to learners and algebraic formalization is supported through LOGO procedures. Furthermore learners 
are afforded opportunities to try out ideas and modify plans, which are essential elements of mathematical problem solving. Students can make and test conjectures, a vital component of mathematical reasoning (Jones 2005). These studies have confirmed Papert's claim that by learning LOGO the child is behaving as a mathematician. Papert proposes that active learning brought about through LOGO is based on the theories of Piaget. However Bruner's work is closer to LOGO in that he postulates that learning is enactive, iconic and symbolic. Firstly learners physically manipulate the Turtle, then they direct the pictorial Turtle on the screen and thirdly they write procedures in LOGO which is symbolic (Ernest 1989).

A view opposing that of Papert is provided by Kurkland and Pea (1985: 241) who refer to Papert's theory as "idealistic individual Piagetian learning." They suggest that self-guided discovery needs to be "mediated within an instructional context” (ibid.).

However Papert's theory is of particular relevance to the previously disadvantaged learners in South African primary schools. Given the oppressive educational system and socio-economic circumstances that their communities and especially the immediate adults that they interact with on a daily basis come from, the materials for constructing their intellects that their cultures provide them with are both insufficient and perfect for perpetuating cultural block. Therefore Papert's proposition of using computers to overcome these cultural barriers to learning is a central focus of this study.

An important aspect of learning algebra through the use of LOGO is the use of variables. A body of research suggests that learners have difficulty in understanding that a letter can represent a range of values (Booth 1984; Collis 1974; Kuchemann 1981). Furthermore they do not accept that the different letters can represent the same value. However the use of LOGO seems to overcome this obstacle. Studies have indicated that learners perceive a variable in LOGO as representing a range of numbers (Noss 1986; Sutherland 1989). Within a LOGO environment they have little difficulty in accepting that any variable name can be used and that different names could represent the same value.

Following from the previous paragraph it can be argued that the use of LOGO entails the learning of concepts which affect the understanding of deep structures. Chomsky (1968) espoused that deep structures of the brain are inborn. One implication of this is that learning new languages does not change the way you think or what you think about, as this would be a surface structure, but learning new concepts would do this.

\subsection{Pre-Mathematical Frames}

Acquisition of conceptual understanding is influenced by prior knowledge (Kintsch 1988). For example, prior knowledge is expected to facilitate the acquisition of conceptual understanding by enhancing students' abilities to assimilate and integrate new information and distinguish relevant from irrelevant information (Alao and Guthrie 1999). This study refers to prior knowledge as pre-mathematical frames, as espoused by Davis (1984). In order to deal with abstract and complex concepts learners make use of their cognitive pre-mathematical frames which were developed in their early years. In part we do this by constructing cognitive 'collages', metaphors based on simple ideas that children learn early in life. In their elaborated form these collages embrace categorical algebra and nonstandard analysis and all the rest of modern mathematics (Davis 1984: 177). Therefore these collages play a major role in shaping our thinking. This study will show how pre-mathematical frames influence the learning process. 


\section{METHOD}

\subsection{Research Site}

Purposive sampling was used to select the research site. This sampling method was used because the sample was likely to provide information-rich data about the phenomena being investigated (White 2003). Due to the nature of the research the selected school had to meet certain criteria. These criteria were:

- $\quad$ A fully networked computer laboratory with at least 20 computers.

- $\quad$ A server to handle the appropriate software.

- $\quad$ VNC Viewer 4 to enable the researcher to remotely access the learners' computers.

- $\quad$ The school population had to be drawn from a disadvantaged socio-economic community thus reflecting the wider South African scenario.

The school that met these criteria is situated in Isipingo, south of Durban. This school serves the surrounding socio-economically disadvantaged communities. The school had a newly installed fully equipped computer laboratory which met all of the aforementioned requirements.

\subsection{Participants}

The participants were selected through a process of purposive sampling. The sample was composed of elements which contained the most characteristic and representative attributes of the learner population (McMillan and Schumacher 1997). Age was not a significant factor in the sampling process due to the participants being in the same Grade. It follows naturally that learners in Grade 5 would fall in the 10-11 year age group. A sample of 20 learners each were selected for the experimental and control groups respectively. The control group which was exposed to the teaching and learning of area through traditional classroom based methods comprised 11 males and 9 females. The experimental group which used collaborative computing as a means of learning area consisted of 12 males and 8 females. These proportions of males to females were a fair reflection of the school population as a whole.

The participants were from disadvantaged socio-economic communities with minimal or no access to computers. Furthermore the participants received negligible academic stimuli from their immediate families. The teaching methods employed at the school were strictly traditional and adhered to the Department of Education guidelines.

\subsection{Measures}

For the purpose of this study two research instruments were used for collecting data. These included questionnaires and a focus group interview.

The first questionnaire, which was aimed at the experimental group, was divided into four sections. Section A was designed to elicit biographic information from the respondents. These included questions on age and gender. Section B included both open and closed questions that looked at the concepts of square, rectangle and area. Questions were also structured to elicit responses about learners' prior knowledge and if and how it influenced their ability to perform calculations. The open ended questions were designed for the respondents to express their ideas and feelings about specific issues. It was the researcher's intention for these questions to provide "rich information" to enhance the findings of this study. Section C comprised closed questions about specific aspects related to learners' perceptions about using, LOGO mathematics and a networked computing environment. The final section (Section D) consisted of two questions which were aimed at obtaining a list of additional mathematical concepts that learners may have learned during their activities. The second questionnaire, which was aimed at the control group, differed only in Section $\mathrm{C}$ which comprised closed questions about specific aspects related to learners' perceptions about learning area in a traditional teaching/learning environment. 
One focus group interview was conducted. The interview was approximately 15 minutes. In determining the size of the group the researcher considered Greeff's (2002: 311) argument that "smaller groups ... are preferable when the participants have a great deal to share about the topic or have intense or lengthy experiences with the topic of discussion." With this in mind the researcher opted for a group of 8 participants. Although the groups were homogenous in that all participants were in the same age range and all were in the experimental group, the researcher also looked at heterogeneity. Gender was represented in proportion to the learner population with 5 males and 3 females being used. This was necessary to elicit diverse opinions and experiences so as to increase the quality and richness of the data obtained. Many authors like Greeff (2002), McMillan and Schumacher (1997), Terre Blanche and Durrheim (1998) advise that focus groups need to rely on purposive sampling where the researcher looks for particular participants so as to obtain a wide range of opinions and experiences. As previously mentioned, the focus group interviews were used to probe certain issues. Thus the questions were open ended. This aimed at eliciting responses from the learners about their perceptions and experiences regarding the learning of area through the use of LOGO.

Furthermore the researcher was also able to gather data on the actual thought processes used by learners through the use of a computer program called VNC Viewer 4 which enabled the researcher to remotely access the learners' computers while they were doing their activities on area.

\subsection{Teaching Method}

The control group approached the concept of area in a conventional manner. Learners were asked to construct squares and rectangles and to divide these shapes into equal units. They then counted the squares to determine area. The experimental group used Logo on their computers. They used the program to determine the number of units in each shape. Thereafter the groups attempted finding formulae to calculate area.

\section{ANALYSIS AND DISCUSSION}

\subsection{Questionnaires}

The results obtained from the analysis of the questionnaires are presented in the form of a comparison between the control group and the experimental group.

\subsubsection{Explanation Of Area}

In the experimental group $85 \%$ of learners were able to explain the meaning of area. Some of their responses are depicted below:

- $\quad$ The number of units in a shape.

- $\quad$ The amount of units covering a shape

- What you get when you measure the surface of a shape

However, only $5 \%$ of the control group was able to explain the concept of area. Some of the responses of the other 95\% were:

- $\quad$ A piece of land

- $\quad$ Where you live

- $\quad$ You times the length, breadth and height

- How long a shape is

- $\quad$ Measure in centimetres

Since this data was obtained after each group was subjected to the learning of area using traditional methods (control group) and computers through the use of Logo and a networked environment (experimental group), the 
analysis illustrates that the latter had gained a better understanding of the concept of area (Figure 3). The errors that learners made in explaining the concept of area may be attributed to pre-mathematical frames (Davis 1984). This will be discussed in greater detail in 4.1.6.

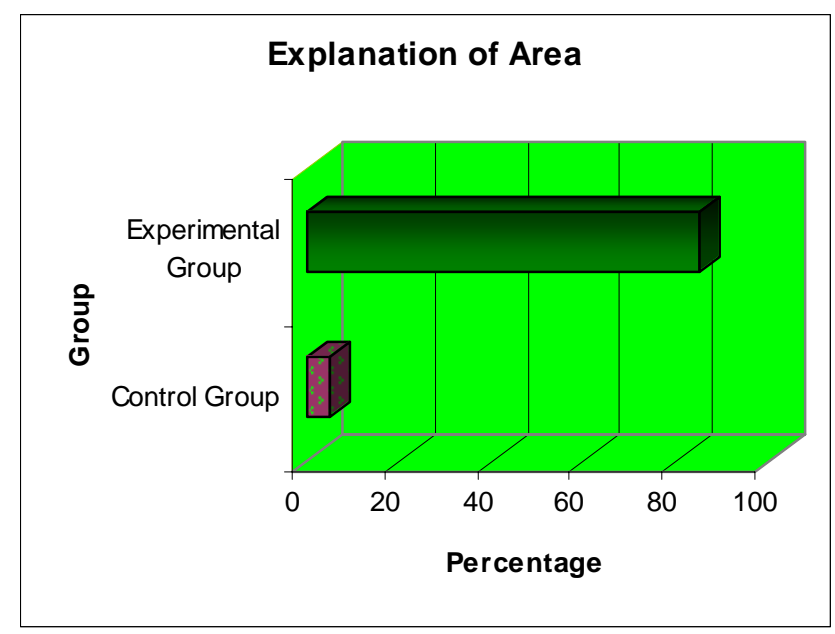

Figure 3: Understanding of the concept of area

\subsubsection{Pre-Knowledge Of Square}

$70 \%$ (14) of the respondents indicated that they had prior knowledge of a square while $30 \%$ (6) responded that they did not have prior knowledge. This is in contrast to the experimental group where $100 \%$ of respondents had prior knowledge of a square. This contrast is illustrated in figure 4. This response was of significance as one of the theories discussed earlier espoused that pre-knowledge frames played an important role in shaping learners' abilities to deal with more abstract problems (Davis 1984). Therefore this would impact on the ability of learners to formulate methods to calculate area of a square. As will be discussed later it becomes evident that learners with a pre-knowledge of squares are better able to formulate ways to calculate area.

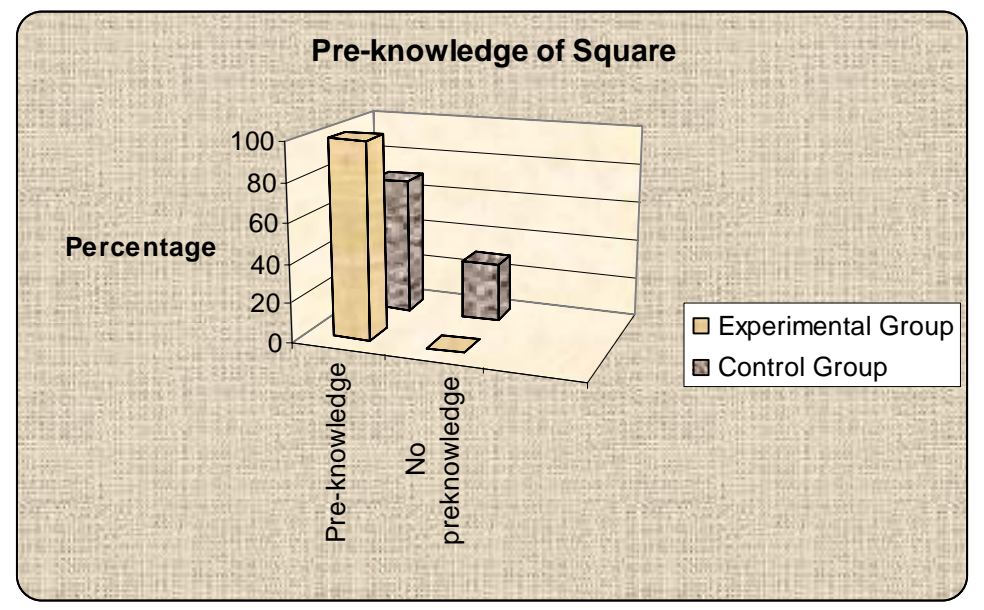

Figure 4: Comparison of sample learners' pre-knowledge of a square 


\subsubsection{Pre-Knowledge Of Rectangle}

$75 \%$ (15) of the respondents in the control group indicated that they had prior knowledge of a rectangle while $25 \%$ (5) responded that they did not have prior knowledge. This is in contrast to the experimental group where $100 \%$ of respondents had prior knowledge of a rectangle. This contrast is illustrated by figure 5 . As in the case of the square this response was of significance as one of the theories discussed in the literature review espoused that preknowledge frames played an important role in shaping learners' abilities to deal with more abstract problems (Davis 1984). Furthermore the analysis will show that learners with a pre-knowledge of rectangles were better equipped to formulate methods of calculating area.

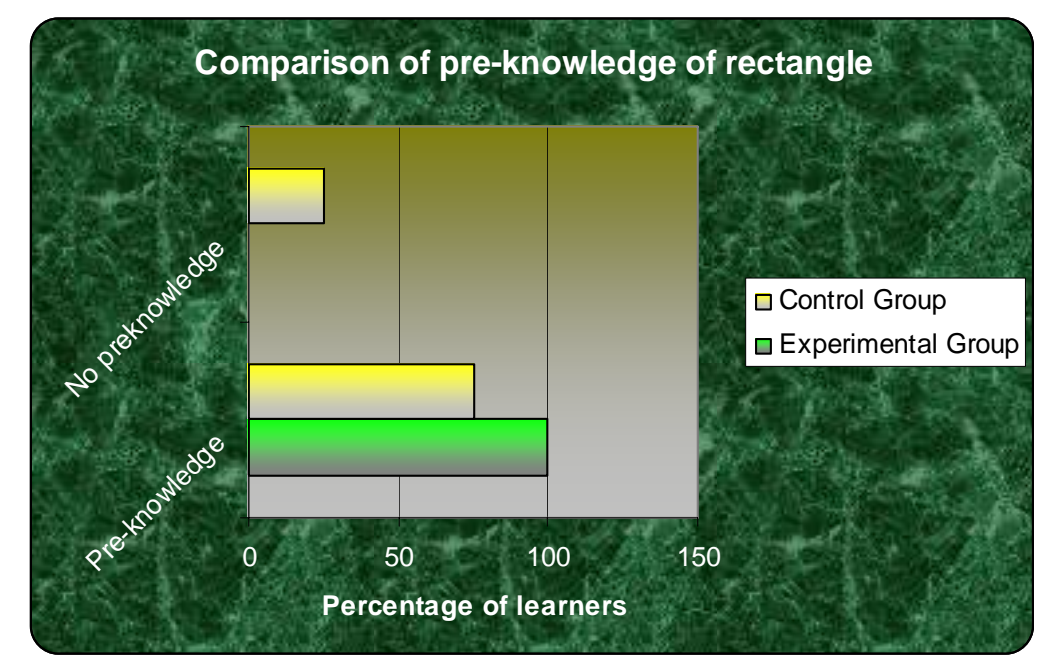

Figure 5: Comparison of sample learners' pre-knowledge of a rectangle

\subsubsection{Manner In Which Pre-Knowledge Of Squares And Rectangles Assisted In Developing Formulae To Calculate Area}

In the experimental group this question was answered by 19 learners. 89.5\% (17) of the respondents indicated that they used the properties of the square and rectangle to develop formulae. Following are exemplars of their answers.

- $\quad$ I knew that a square has 4 equal sides. Then if I know what 1 side measures all I had to do was to multiply it by itself.

- $\quad$ Since all the sides of a square are the same you multiply any side by itself.

- $\quad$ The rectangle has 2 long sides which are equal to each other and 2 short sides which are equal to each other. That is why you multiply 1 short side by 1 long side.

The fact that $89.5 \%$ of the respondents were able to develop formulae based on their pre-knowledge illustrates the importance of the latter in enhancing learners' abilities to assimilate and integrate new information (Alao and Guthrie 1999). Furthermore this finding is in contrast to Piaget's stages of cognitive development which places 10 - 11 year old learners in the concrete operational stage (Berk 2000). Since these learners were capable of developing formulae to calculate area they are operating at Piaget’s formal operational stage.

In the control group 35\% (7) of learners responded to this question. In keeping with the information garnered from the previous questions the following examples of their responses depict the difficulty they had in formulating formulae due their limited pre-knowledge of the properties of squares and rectangles (Davis 1984). 
- $\quad$ Knowing the properties makes it easier to add and multiply.

- $\quad$ I know what a square is so I added 2 and 2

- $\quad$ Because I knew how many sides a square had and how many sides a rectangle had.

- $\quad$ By the shapes. The square has 4 sides and the rectangle has 3(sic) sides.

Therefore when comparing the responses of the learners in the experimental group to those of the learners in the control group, the importance of pre-knowledge frames as espoused by Davis (1984) and Kintsch (1988) seems to be vindicated.

\subsubsection{Perceptions Of Learners Regarding Teaching/Learning Methods}

Table 1 reflects the attitudes of the control group towards the teaching/learning methods employed during their activities on area.

Table 1: Control group perceptions of teaching /learning methods

\begin{tabular}{|l|c|}
\hline \multicolumn{1}{|c|}{ Variable } & Percentage \\
\hline a. I was allowed to try my own methods & 0 \\
\hline b. I felt confident trying my own method after the lesson & 50 \\
\hline c. I did not fear getting answers wrong because of feedback from the educator & 30 \\
\hline d. I felt in control of the lesson & 20 \\
\hline e. I was able to share ideas with other learners & 60 \\
\hline
\end{tabular}

Table 2 reflects the attitudes of the experimental group towards the teaching/learning methods employed during their activities on area.

Table 2: Experimental group perceptions of teaching /learning methods

\begin{tabular}{|l|c|}
\hline \multicolumn{1}{|c|}{ Variable } & Percentage \\
\hline a. I was allowed to try my own methods & 100 \\
\hline b. I felt confident trying my own method & 100 \\
\hline c. I did not fear getting answers wrong because feedback from the computer made me feel at ease & 100 \\
\hline d. Giving the computer instructions made me feel in control & 95 \\
\hline e. Sharing ideas through the computer improved my understanding of the lesson & 100 \\
\hline f. Being able to share my ideas with the entire class on the LAN made me feel important & 100 \\
\hline
\end{tabular}

When comparing the perceptions of the control group (Table 1) and experimental group (Table 2) it is apparent that the learning experiences of the latter vindicates the theories postulated in this study. This is elaborated upon in the following subsections which examine the perceptions of the experimental group in more detail. The percentages are not reflected in each subsection as all bar 4.1.5.1 (95\%) were 100\%.

\subsubsection{Freedom To Try Own Methods}

This finding is in line with the constructivist approach in that learners are encouraged to develop their own tasks (Jolliffe et al 2001). It also finds support in the theory of Papert (1980) who views children as builders constructing their own intellectual structures. Therefore they need to be afforded the opportunity to explore different avenues of finding solutions. Finally it blends in with use of LOGO mathematics which allows learners to try out ideas and modify plans as well as make and test conjectures (Jones 2005). 


\subsubsection{Confidence In Implementing Own Method}

This finding is vindicated by the exposition of Papert (1980) that the use of LOGO mathematics through the medium of computers overcomes cultural barriers. The fact that these learners are comfortable in trying their own methods to find mathematical solutions despite coming from a culture that provides minimal material resources as far as mathematics is concerned, further justifies the previous point.

\subsubsection{Positive Feedback From The Computer}

The learners' response to this question may be clarified through comparison with the views of Papert (1980). Central to Papert's postulation, and as evident in the findings in this question, is that the learners' interaction with LOGO via the computer is not a one-way process. The program provides feedback in such a manner as to provide learners with a choice as to how they want to react to it (Papert 1980).

\subsubsection{Control}

The finding in this question that $95 \%$ of the respondents felt in control when giving the computer instructions, through the use of LOGO, is supported by the view that in the LOGO environment the learner assumes the role of instructor and programmer (Papert 1980). Furthermore these learners are overcoming cultural block through the use of Logo by feeling in control of a mathematical situation which is in direct contrast to their surrounding cultural influences.

\subsubsection{Sharing Of Ideas}

The responses of the learners highlight the value of collaborative learning through the use of computers. Proponents of collaborative learning claim that shared learning enables learners to be responsible for their own learning, become critical thinkers and engage in discussion (Totten, Sills, Digby and Russ 1991 as cited by Gokhale 1995).

\subsubsection{Self-Belief}

This finding is supported by theory which states that collaborative learning implies that learners are responsible for the learning of other group members as well as their own and as a result success or failure is shared (Totten, Sills, Digby and Russ 1991 as cited by Gokhale 1995). Furthermore it is evident that these learners are overcoming their cultural barriers to learning mathematics as they are learning to use computers, and a networked computing environment in particular, in a way that is gifting them with the confidence to share their ideas with others without fear (Papert 1980).

\subsubsection{Other Mathematical Concepts Discovered During This Activity}

All 20 (100\%) respondents in the experimental group and 10 (50\%) in the control group indicated that they had learned additional mathematical concepts during the course of the activities. According to Papert (1980), using LOGO mathematics through computers can change the way learners learn everything else. Furthermore this may imply that the use of LOGO through the medium of computers enables learners to think on a deeper level by relating other concepts to their activities. Therefore LOGO is affecting the way learners think and what they think about. This in turn can be linked to the theory of Chomsky (1968) because LOGO is thus facilitating the learning of new concepts which affect the understanding of deep structures. The following tables list the additional concepts that the respective groups claimed to have learned.

Table 3: List of additional mathematical concepts discovered by the experimental group 


\begin{tabular}{|c|c|}
\hline Concepts & Number of Learners \\
\hline Formula & $15(75 \%)$ \\
\hline Polygons & $14(70 \%)$ \\
\hline Angles & $13(65 \%)$ \\
\hline Variables & $9(45 \%)$ \\
\hline Equations & $8(40 \%)$ \\
\hline Circle & $3(15 \%)$ \\
\hline Symmetry & $3(15 \%)$ \\
\hline Volume & $2(10 \%)$ \\
\hline Fractions & $1(5 \%)$ \\
\hline Measurement & $1(5 \%)$ \\
\hline Patterns & $1(5 \%)$ \\
\hline
\end{tabular}

The fact that significant percentages of learners listed concepts like formula and variables shows that these learners are operating at Piaget's formal operational stage yet their age group places them in the concrete operational stage (Berk 2000). This can be attributed in part to the impact of LOGO. A body of research puts forth the idea that learners working with LOGO, by creating and interacting with objects that are visible, quantifiable, and adhere to conventional mathematics, build connections between spatial and algebraic thinking. Furthermore algebraic formalisation is supported through LOGO procedures (Jones 2005). The responses in this question also reinforce the notion that the use of LOGO contributes to dispelling the impact of cultural barriers to learning mathematics.

Table 4: List of additional mathematical concepts discovered by the control group

\begin{tabular}{|c|c|}
\hline Concepts & Number of Learners \\
\hline Formula & $2(10 \%)$ \\
\hline Addition & $1(5 \%)$ \\
\hline Multiplication & $3(15 \%)$ \\
\hline Shapes & $1(5 \%)$ \\
\hline Measurement & $1(5 \%)$ \\
\hline
\end{tabular}

It is evident that the control group, using traditional teaching/learning methods, discovered fewer additional mathematical concepts than the experimental group. This indicates that the traditional method fails to address the issue of cultural barriers.

While the learning of additional concepts during the activities of area is positive, it is apparent that some of the concepts listed bear little relation to what was being learnt. Such an example is the concept of volume which was listed by $10 \%$ of the experimental group. This may be linked to the theory of pre-mathematical frames where learners construct collages from simple ideas that they learn early in life. These collages are then used to handle more complex mathematical problems later in life (Davis 1984). Thus it follows that if an inaccurate understanding of a concept is inculcated along the way, a flawed collage will be created. It is possible that the aforementioned learners drew upon their pre-mathematical frames and associated length and breadth, which are also used in the calculation of volume, with area. This may be explained diagrammatically (Figure 6).

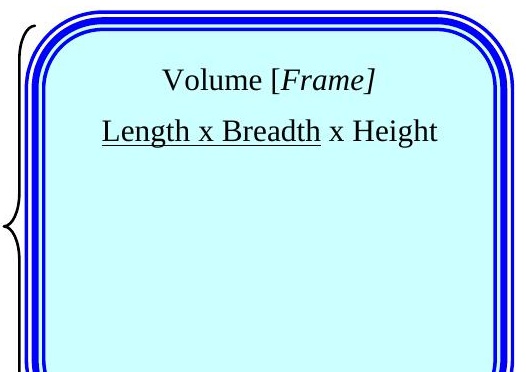


Pre-mathematical Frames

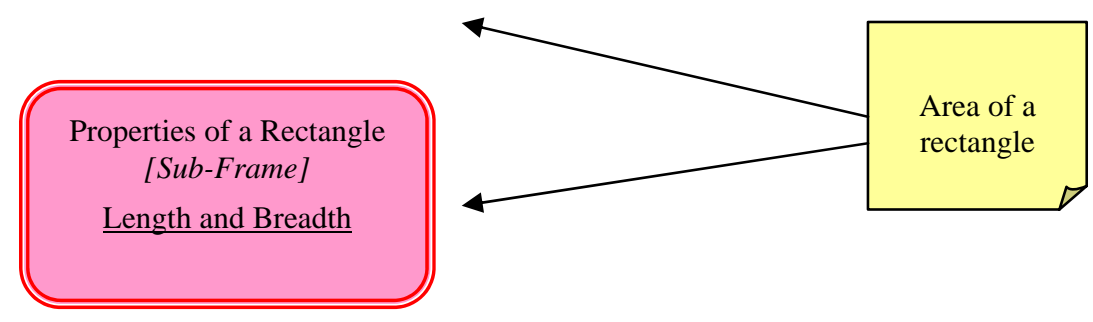

Figure 6: Error associated with pre-mathematical frames

\subsection{Focus Group Interview}

The focus group interview was conducted with 8 members of the experimental group for reasons explained earlier. Discussion of the questions and responses follow.

\subsubsection{Was The Use Of The VNC Viewer Beneficial To Your Learning Experience? Explain.}

The responses were as follows:

- $\quad$ I was able to follow instructions by watching and listening and knew what had to be done.

- $\quad$ I could give ideas through the computer.

- $\quad$ The teacher and my friends could show me things on my computer.

The first response clearly shows the value of the VNC Viewer as an instructional tool since it incorporates both visual and audio elements. Furthermore it allows for input by clients thus facilitating a collaborative process. This ties in with the other 2 responses which also indicate the value attached to collaboration by the learners. This is vindicated by the view that learners are also responsible for the learning of their peers (Gokhale 1995). Furthermore the point that learners were allowed the opportunity to share their own ideas with others, including the educator, illustrates the degree to which cultural block and cultural barriers to the learning of mathematics are overcome (Papert 1980). Finally, from the view of the educator, the VNC Viewer provides an excellent medium to observe learners thought processes as they engage in mathematical activities.

\subsubsection{How Did The Use Of Logo Assist You To Develop Formulae To Calculate Area?}

The responses were as follows:

- $\quad$ I followed the patterns provided.

- $\quad$ Building the shapes helped me see which sides were equal and I followed the corrections the computer gave me.

Thus the nature of the Logo program which allows for interaction and constructive feedback assisted learners in their activity. The learners' interaction with LOGO via the computer is not a one-way process. The program provides feedback in such a manner as to provide learners with a choice as to how they want to react to it (Papert 1980). It is also apparent that by actively constructing shapes learners were able to gain a clearer understanding of the properties of these shapes thereby enabling them to develop formulae to calculate area.

\subsubsection{What Are Variables?}


The responses received were:

- $\quad$ Letters that stand for numbers.

- $\quad$ One letter can mean many numbers.

- $\quad$ Many letters may stand for the same number.

- $\quad$ Example: $4 \mathrm{x}$ a

If $\mathrm{a}=4$ then the answer is 16 .

A body of research suggests that learners have difficulty in understanding that a letter can represent a range of values (Booth 1984; Collis; 1974; Kuchemann 1981). Furthermore they do not accept that the different letters can represent the same value. However the use of LOGO seems to overcome this obstacle. Studies have indicated that learners perceive a variable in LOGO as representing a range of numbers (Noss 1986; Sutherland 1989). Within a LOGO environment they have little difficulty in accepting that any variable name can be used and that different names could represent the same value. In addition variables reinforce the notion that area is dynamic as the former affect the area of a shape.

\subsubsection{Can You Link The Activities On Area To Your Everyday Life? Provide Examples.}

The responses were:

- $\quad$ We see shapes all around us.

- We use shapes to make things.

- We have to be able to find short ways to measure to build things like a volleyball court. We must know a rectangle.

- $\quad$ Our houses are made of different shapes like squares and rectangles.

- $\quad$ If we buy a new TV we should know its area to see if it fits in the unit.

It is apparent from the responses that the learners are able to relate their activities to their everyday lives. Further this is evidence that the learners are removing the obstacle of cultural barriers by being able to apply mathematics to their everyday life situations. Thus they are being given meaning and they are giving meaning to mathematics (Papert 1980).

\section{CONCLUSION}

Analysis of the data collected through the questionnaires and focus group interview show a significant disparity in the learning experiences of the control group, which attempted activities on area using traditional classroom teaching and learning methods, and the experimental group which conducted their activities on area using Logo mathematics in a networked computer laboratory. The results show that pre-mathematical frames played a significant role in determining the manner in which learners were able to develop formulae to calculate area based on their pre-knowledge of the properties of squares and rectangles (Davis 1984). Furthermore the learners in the experimental group had to a large extent overcome the cultural barriers (Papert 1980) towards mathematics that had been inculcated in them by their immediate community, by displaying an enthusiasm to share ideas and to allow others to have access to their thought processes via the local area network. Finally the data shows that the experimental group grasped a better understanding of the concept of area. This may be attributed to a combination of pre-mathematical frames, collaborative learning in a networked computing environment and the use of Logo mathematics.

\section{ACKNOWLEDGEMENTS}


This study was supported by the Durban University of Technology and National Research Foundation, South Africa.

\section{REFERENCES}

1. Alao, S. and Guthrie, J.T. (1999) Predicting Conceptual Understanding with Cognitive and Motivational Variables. The Journal of Educational Research, 92(4), 243-253.

2. $\quad$ Berk, L.E. (2000) Child Development. $5^{\text {th }}$ Edition. Needham Heights, MA: Allyn and Bacon. Babbie, E. (1990) Survey Research Methods. $2^{\text {nd }}$ Edition. California: Wadsworth, Inc.

3. Booth, L. (1984) Algebra: Children's Strategies and Errors. Winsdor: NFER-Nelson.

4. Chomsky, N. (1968) Linguistic Contributions to the Study of Mind (Future). Language and Mind. Available online at: http://www.marxists.org/reference/subject/philosophy/index.htm. (Accessed 28 August 2006).

5. Collis, K.F. (1974) Cognitive development and mathematics learning. In Proceedings of the Psychology of Mathematics Education Workshop. London: Chelsea College Centre for Science Education.

6. Davis, R.B. (1984) Learning Mathematics: The Cognitive Science Approach to Mathematics Education. Kent: Croom Helm Ltd.

7. Ernest, P. (1989) What's the Use of LOGO? In Ernest, P. (Ed.) Mathematics Teaching: The State of the Art. East Sussex: The Falmer Press: p. 33-44.

8. Gokhale, A.A. (1995) Collaborative Learning Enhances Critical Thinking, [online], JTE, http://scholar.lib.vt.edu/ejournals/JTE/v7n1/gokhale.jte-v7n1.html. (Accessed 24 February 2006).

9. Greeff, M. (2002) Information Collection: interviewing. In de Vos, A. S., Strydom, H., Fouche, C. B. and Delport, C. S. L. (Eds.) Research at Grass Roots, 2nd Edition. Pretoria: Van Schaik: p. 311-319.

10. Hoyles, C. (1985) Developing a context for Logo in school mathematics. Journal of Mathematical Behaviour, 4(3), 237-256.

11. Huitt, W. and Hummel, J. (2003) Piaget's theory of cognitive development. Psychology Interactive. Available online at: http://chiron.valdosta.edu/whuitt/col/cogsys/piaget.html. (Accessed 28 August 2006).

12. Jolliffe, A., Ritter, J. and Stevens, D. (2001). The Online Learning Handbook: Developing and Using WebBased Learning. London: Kogan Page Limited.

13. Jones, K. (2005) Using Logo in the Teaching and Learning of Mathematics: a research bibliography. MicroMath, 21(3), 34-36.

14. Karuppan, C. M. (2001). Web-based teaching materials: a user's profile. Internet Research: Electronic Networking and Applications Policy, 11(2), 181-194.

15. Kintsch, W. (1988) The role of knowledge in diverse comprehension: A construction-integration model. Psychological Review, 95, 163-182.

16. Kuchemann, D.E. (1981) Algebra. In Hart, K. (Ed.) Children's Understanding of Mathematics. London: Murray. p. 11-16

17. Kuhn, D., Langer, J., Kohlberg, L. and Haan, N.S. (1977) The development of formal operations in logical and moral judgement. Genetic Psychology Monographs, 95, 97-188.

18. Kurkland, D.M. and Pea, R.D. (1985) Children's Mental Models of Recursive LOGO Programs. Journal of Educational Computing Research. Available online at: http://scil.stanford.edu/about/staff/bios/pea.html. (Accessed 19 December 2006).

19. McMillan, J. and Schumacher, S. (1997) Research in Education: A Conceptual Introduction. $4^{\text {th }}$ Edition. New York: Longman.

20. Naidoo, N. and Naidoo R. (2006a) Enhancing the learning experience of primary school learners through the utlisation of a hybrid web-based learning model. In Proceedings of the $17^{\text {th }}$ International Conference of the Society for Information Technology and Teacher Education, Vol. 4, p. 2341.

21. Naidoo, N. and Naidoo R. (2006b) Improving Visual and Verbal Skills of Primary School Learners Through Effective Web-Based Learning. In Proceedings of the International Conference on e-Learning, p. 347.

22. Naidoo R. (1998) Errors made in differential calculus. In Proceedings of the $22^{\text {nd }}$ Conference of the International Group for the Psychology of Mathematics Education, Vol. 4, p4-288.

23. Noss, R. (1986) Constructing a conceptual framework for elementary algebra through Logo programming. Educational Studies In Mathematics, 17(4), 335-357. 
24. Noss, R. (1998) The Computer as a Cultural Influence in Mathematical Learning. Educational Studies in Mathematics, 19, 251-268.

25. Papert, S. (1980) Mindstorms: Children, Computers and Powerful Ideas. Sussex: The Harvester Press Limited.

26. Renner, J., Stafford, D., Lawson, A., McKinnon, J., Friot, E. and Kellog, D. (1976) Research, teaching, and learning with the Piaget model. Norman, OK: University of Oklahoma Press.

27. Sutherland, R. (1989) Providing a computer based framework for algebraic thinking. Educational Studies in Mathematics, 20(3), 317-344.

28. Terre Blanche. M. and Kelly, K. (1999) Interpretive Methods. In Terre Blanche, M. and Durrheim, K. Research in Practice. Applied Methods for the Social Sciences. Cape Town: University of Cape Town Press (Pty) Ltd. p.388.

29. White, C.J. (2003) Research Methods and Techniques. Pierre van Ryneveld: CJ White.

\section{NOTES}

